\title{
Aditivo surfactante de fonte renovável para redução do consumo energético na extrusão de massas de cerâmica vermelha
}

\section{(Surfactant additive from renewable source for reduction of energy consumption in the extrusion of red ceramic masses)}

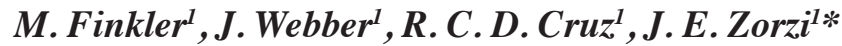 \\ ${ }^{1}$ Universidade de Caxias do Sul, Instituto de Materiais Cerâmicos, 95765-000, Bom Princípio, RS, Brasil
}

\begin{abstract}
Resumo
O impacto de surfactantes na extrusão semiúmida de massas argilosas está diretamente relacionado ao desempenho associado à vazão mássica e respectivo consumo energético. Neste trabalho foi elaborada uma formulação baseada em uma massa empregada na fabricação de blocos estruturais aditivada com surfactante obtido de fonte renovável (tanino). O objetivo foi avaliar os impactos da adição do tanino na trabalhabilidade da massa, na redução do consumo de energia, na dureza do extrudado e nas propriedades dos corpos secos e sinterizados, i.e., resistência à flexão, retração linear e absorção de água. Na formulação com 1,0\% em massa de tanino os resultados indicaram diminuição de $\sim 37 \%$ da dureza da massa úmida, aumento da resistência mecânica após secagem ( $29 \%)$ e queima ( 15\%) e redução de $\sim 75 \%$ no consumo energético específico. O efeito global da adição sugere que o tanino pode ser utilizado, salvaguardando-se os critérios econômicos, sem comprometer a manutenção do desempenho dos blocos de cerâmica vermelha.
\end{abstract}

Palavras-chave: surfactante, extrusão, argila, tanino.

\begin{abstract}
The impact of surfactants on the semi-solid extrusion of clay masses is directly related to the performance associated with the mass flow and energy consumption. In this work, a formulation based on a ceramic mass used in the manufacture of structural blocks was formulated with the addition of surfactant obtained from a renewable source (tannin). The objective was to evaluate the impacts of tannin addition on the workability of the mass, reduction of energy consumption, the hardness of the extrudate, and properties of the dry and sintered bodies (e.g. flexural strength, linear retraction and water absorption). For the ceramic mass formulation with $1.0 \mathrm{wt} \%$ tannin, the results indicated a decrease of $\sim 37 \%$ in wet mass hardness, increase in mechanical strength after drying ( 29\%) and firing $(\sim 15 \%)$, and $\sim 75 \%$ reduction in specific energy consumption. The overall positive effects of surface modifier addition to the ceramic mass suggest that tannin can be used, safeguarding the economic criteria, without compromising the performance of the red ceramic blocks.
\end{abstract}

Keywords: surfactant, extrusion, clay, tannin.

\section{INTRODUÇÃO}

O processo de fabricação de produtos cerâmicos estruturais à base de silicatos ou óxidos sintéticos avançados inclui uma etapa de conformação, seguida geralmente por etapas de secagem e queima. É na etapa de conformação que as principais características geométricas do produto cerâmico acabado são definidas. Em diversas técnicas de processamento, o produto é conformado a partir de uma formulação constituída por uma ou mais matérias-primas cerâmicas, aditivos auxiliares e um fluido. A principal função do fluido, também chamado de veículo, é permitir

*jezorzi@ucs.br o transporte do pó e conferir trabalhabilidade à mistura. Em muitos casos, este veículo é a água. A metodologia de preparação de massas cerâmicas homogêneas e com grau de trabalhabilidade adequado, que possam ser conformadas com relativa facilidade, deve ser escolhida de acordo com as características das matérias-primas e do processo de conformação envolvido. No entanto, independente do processo de conformação, o teor de sólidos na massa deve ser tão elevado quanto possível, de modo a reduzir o volume de água a ser removido, reduzir a retração e minimizar a formação de defeitos de secagem. Por outro lado, processar formulações com elevado teor de sólidos pode resultar na diminuição da trabalhabilidade da massa e dificultar sua conformação, principalmente na extrusão semiúmida. 
Grande parte dos desafios encontrados no processamento de massas cerâmicas pode ser rastreada até o mecanismo de interação entre a matéria-prima cerâmica e o veículo. A intensidade e o tipo de interação físico-química entre os componentes da massa cerâmica determinam o estado de dispersão das partículas. O estado de dispersão das partículas, por sua vez, tem influência sobre o comportamento reológico (trabalhabilidade/escoamento da mistura), empacotamento, estabilidade dimensional e, finalmente, impacta na formação de defeitos no corpo cerâmico após a queima. A tendência natural das partículas cerâmicas é a aglomeração, devido à elevada área e reatividade superficial e pelo domínio das forças atrativas de van der Waals $[1,2]$. Um efeito imediato é o aprisionamento de líquido dentro dos espaços intersticiais dos aglomerados. Desta forma, o teor efetivo de líquido que atua como veículo é reduzido e a viscosidade da mistura aumenta. Para compensar esse efeito é necessário aumentar o teor de água na massa. Outra consequência da presença de aglomerados é a heterogeneidade na microestrutura do cerâmico conformado, tais como vazios e poros. A má dispersão das partículas cerâmicas no estágio inicial do processo pode resultar em contração não uniforme e defeitos, os quais podem comprometer a resistência mecânica do componente final [3-5]. Formulações cerâmicas com propriedades reológicas adequadas e com arranjos homogêneos de partículas podem ser obtidas quando as partículas estão controladamente dispersas [1]. Um método de evitar a aglomeração e promover a dispersão das partículas consiste em adicionar moléculas orgânicas à mistura $[2,6]$. Certas moléculas adsorvem na superfície das partículas e criam um impedimento físico estérico e/ou elétrico [1]. Desta forma são criadas forças repulsivas, as quais mantêm as partículas afastadas em posições definidas de equilíbrio e promovem sua dispersão.

Para dispersar partículas cerâmicas é possível utilizar aditivos surfactantes obtidos de fontes renováveis. Florestas e bosques são fontes potenciais destas matériasprimas. A acácia negra (Acacia mearnsii) é uma árvore nativa da Austrália e foi introduzida no Brasil em 1918. Esta árvore é cultivada no Rio Grande do Sul e representa uma parcela significativa do plantio de reflorestamento no Estado, principalmente em regiões próximas aos centros consumidores [7, 8]. Diferente de outras árvores, e.g. quebracho, que possibilitam a partir do seu cerne a extração de compostos orgânicos, e.g. resinas e gomas, é na casca da acácia negra que se concentra a principal parcela de compostos extraíveis economicamente, entre eles os taninos. Os taninos são considerados compostos polifenólicos, macromoleculares, solúveis em água, capazes de interagir com substâncias orgânicas ou inorgânicas e são classificados em dois grupos principais: hidrolisáveis ou condensados [913]. Os taninos condensados são constituídos por oligômeros de diferentes massas molares, formados pela condensação de unidades monoméricas flavan-3-ol [14, 15]. A unidade flavan-3-ol sofre hidroxilação em diferentes posições. Pode ocorrer condensação de 2 até 50 unidades flavan-3-ol, resultando em estruturas com massas molares médias de 500 a $3000 \mathrm{~g} / \mathrm{mol}$ [11-13] e podem chegar até $20000 \mathrm{~g} / \mathrm{mol}$ [10, 13].

O impacto dos aditivos de processamento na extrusão de massas típicas para cerâmica vermelha está diretamente relacionado ao desempenho do processo de conformação, vazão da massa e ao consumo energético do equipamento, isto é, ao aumento da vazão e/ou redução do consumo energético para um mesmo conteúdo de água. Devido à dispersão eficiente das partículas, com consequente redução da viscosidade da mistura, aditivos dispersantes podem também reduzir o volume de água necessária na extrusão e, dessa forma, colaborar com a redução do consumo energético na secagem. Finalmente, aditivos dispersantes também podem permitir a utilização de matérias-primas de baixa plasticidade, como as disponíveis no Vale do Caí, uma vez que facilitam seu escoamento no processo de extrusão. No início do século XX, Acheson mostrou que adicionar uma pequena quantidade de tanino na argila não só aumentava o limite de escoamento de uma massa plástica, como também aumentava sua plasticidade e reduzia a retração na secagem em aproximadamente 40\% [14-17]. Na última década foram publicados diversos trabalhos utilizando taninos para dispersão de alumina [18-21] e ao menos uma patente para produtos com argila [22]. Porém, para as matérias-primas de baixa plasticidade o efeito de taninos no processo de extrusão, principalmente sobre a possibilidade de redução do consumo energético, ainda não foi estudado.

$\mathrm{O}$ estudo da interação entre aditivos de processamento naturais, como os taninos, e a superfície das partículas cerâmicas de massas argilosas visa reduzir o custo de fabricação e a obtenção de produtos cerâmicos acabados com desempenho superior, i.e., sem comprometer a manutenção dos critérios de conformidade e qualidade que os produtos acabados da cerâmica vermelha, neste caso específico blocos estruturais, devem atender. Tal objetivo deve ser alcançado por meio do controle do comportamento ao escoamento de uma massa cerâmica industrial aditivada com tanino. Sabe-se de estudos anteriores que as matérias-primas do Vale do Caí (RS), em função de sua composição, possuem baixa plasticidade $[23,24]$. Neste trabalho foi selecionado um aditivo de fonte renovável (tanino) comercial para ser utilizado como dispersante em uma massa cerâmica atualmente empregada na indústria do Vale do Caí. Esta massa foi utilizada para a obtenção de corpos de prova por extrusão. Foi verificado o efeito do aditivo surfactante na vazão e dureza da massa úmida e consequentemente no consumo energético específico durante o processamento. Também foram realizados ensaios de caracterização tecnológica, e.g. resistência à flexão a seco e queimado, retração linear e absorção de água, densidade aparente e porosidade aparente dos corpos de prova queimados.

\section{EXPERIMENTAL}

Materiais: foram selecionadas as seguintes matériasprimas: uma massa argilosa utilizada na fabricação de produtos cerâmicos, empregada na indústria de blocos no 
Vale do Caí (RS), codificada como 15-08-007 e, como aditivo, um dispersante de fonte renovável à base de taninos condensados (Tanac, Weibull AQ), codificado como W. Para a caracterização tecnológica (resistência à flexão, retração linear, absorção de água, densidade aparente e porosidade aparente) foram elaboradas duas composições da massa 1508-007 com aproximadamente 30\% em massa de água. A primeira composição foi chamada de A (sem aditivo) e a segunda foi chamada de AW1 (1\% em massa do aditivo W, base seca).

Caracterização da matéria-prima: a massa argilosa foi caracterizada por fluorescência de raios X, difração de raios $\mathrm{X}$ (análise mineralógica qualitativa) e análise térmica simultânea STA (DSC+TG - calorimetria exploratória diferencial+termogravimetria). Análises químicas semiquantitativas foram realizadas em um espectrômetro de fluorescência de raios X (Philips/Panalytical, PW 2400), com tubo de Rh. Para esta análise foram preparadas pastilhas prensadas (20 tonf $/ \mathrm{cm}^{2}$ por $2 \mathrm{~min}$ ) com $7 \mathrm{~g}$ de amostra e 1,4 g de cera (Hoechst Wachs, $\mathrm{C}_{38} \mathrm{H}_{76} \mathrm{~N}_{2} \mathrm{O}$ ), previamente homogeneizadas. Na análise de difração de raios $\mathrm{X}$ também foi utilizado o pó prensado [25-27]. As medidas foram realizadas em um difratômetro de raios $\mathrm{X}$ (Panalytical, Empyrean), com radiação $\mathrm{CuK} \alpha(\lambda=1,54056$ $\AA ̊$ ), operado a $40 \mathrm{kV}$ e $30 \mathrm{~mA}$ de corrente. Para a análise térmica foi utilizado um equipamento da Netzsch (STA 449 F3 Jupiter). Na análise foi utilizada a massa cerâmica sem surfactante, em atmosfera oxidante com $40 \mathrm{~mL} \cdot \mathrm{min}^{-1}$ de ar sintético e fluxo de $20 \mathrm{~mL} \cdot \mathrm{min}^{-1}$ de gás de proteção, com taxa de aquecimento de $10{ }^{\circ} \mathrm{C} \cdot \mathrm{min}^{-1}$ até $1300{ }^{\circ} \mathrm{C}$.

Determinação da umidade de extrusão e dureza do extrudado: a umidade de extrusão (em termos percentuais) foi determinada pela pesagem dos corpos de prova antes e após a etapa de secagem. A dureza do extrudado foi determinada durante o processo de extrusão utilizando um penetrômetro (Geotester). Foram realizadas três medidas para cada amostra (triplicata).

Consumo energético: para avaliação do consumo energético, três diferentes composições foram preparadas com o teor de aditivo igual a $0,25,0,5$ e $1,0 \%$ sobre a massa argilosa. Também foram realizados ensaios com dois teores de umidade na massa sem aditivos (28,5 e 29,3\% em massa, base seca). Neste caso, a variação do teor de aditivo teve por objetivo verificar para qual quantidade de água ocorre a maior redução do consumo energético durante a extrusão. Para cada composição foram preparados $15 \mathrm{~kg}$ de amostra. Antes da elaboração das misturas, a massa foi desaglomerada em moinho de martelos, laminada a rolos e seca em estufa de ventilação forçada a $110^{\circ} \mathrm{C}$ durante $24 \mathrm{~h}$. $\mathrm{O}$ aditivo $\mathrm{W}$ foi adicionado e diluído na quantidade total de água de mistura, em torno de $30 \%$ em massa sobre a base seca de massa que foi extrudada. Essa solução de tanino foi adicionada à massa homogeneizada a qual se encontrava na forma de pó seco. A mistura da massa em pó com a solução de tanino foi realizada em um misturador intensivo (Eirich) durante $3 \mathrm{~min}$ a $15 \mathrm{~Hz}$ (775 rpm) com rotação da cuba de $31 \mathrm{rpm}$. Após a obtenção de uma massa plástica, as misturas das massas foram armazenadas em recipientes lacrados e sazonadas por $24 \mathrm{~h}$ antes de serem extrudadas. Antes da etapa final de extrusão, as massas foram homogeneizadas novamente utilizando uma extrusora (Verdés), com uma frequência de $50 \mathrm{~Hz}$, sem a utilização de vácuo. Com a aplicação de vácuo foram moldados por extrusão 100 corpos de prova de dimensões 20 x 15 x 100 mm para cada composição (A e AW1). Após, os corpos de prova obtidos foram submetidos a ensaios de caracterização tecnológica. Os dados de processamento são apresentados na Tabela I. Para cada formulação foram realizados testes de vazão mássica e consumo de energia na extrusora. As amostras coletadas foram pesadas e a umidade foi determinada em base seca e úmida. Durante o processamento foram coletados dados da corrente de saída $\left(\mathrm{I}_{\text {out }}\right)$ e potência de saída $\left(\mathrm{Kw}_{\text {out }}\right)$ do inversor de frequência da extrusora. Esses dados permitiram determinar a redução do consumo de energia com a utilização de aditivo surfactante.

Tabela I - Configuração padrão para operação da extrusora. [Table I - Standard setting for extruder operation.]

\begin{tabular}{ccc}
\hline $\begin{array}{c}\text { Frequência } \\
(\mathrm{Hz})\end{array}$ & $\begin{array}{c}\text { Velocidade da rosca } \\
\text { (rotações/min) }\end{array}$ & $\begin{array}{c}\text { Pressão } \\
(\mathrm{mmHg})\end{array}$ \\
\hline 20 & 12 & $\geq 700$ \\
\hline
\end{tabular}

Etapa de secagem: primeiramente, os corpos de prova ficaram expostos à temperatura ambiente por um período de $24 \mathrm{~h}$. Em seguida, a secagem foi conduzida de acordo com um ciclo de secagem pré-estabelecido, compreendendo um tempo total de $22 \mathrm{~h}$, conforme mostrado na Tabela II.

Tabela II - Parâmetros de secagem dos corpos de prova. [Table II - Parameters for samples drying.]

\begin{tabular}{ccc}
\hline $\begin{array}{c}\text { Temperatura } \\
\text { inicial }\left({ }^{\circ} \mathrm{C}\right)\end{array}$ & $\begin{array}{c}\text { Temperatura } \\
\text { final }\left({ }^{\circ} \mathrm{C}\right)\end{array}$ & $\begin{array}{c}\text { Tempo } \\
(\mathrm{h})\end{array}$ \\
\hline 35 & 40 & 0,5 \\
40 & 40 & 4,5 \\
40 & 60 & 1 \\
60 & 60 & 6 \\
60 & 110 & 2 \\
110 & 110 & 8 \\
\hline
\end{tabular}

Etapa de queima: para a caracterização tecnológica dos corpos de prova, foram estabelecidos ciclos de queima para cinco temperaturas diferentes: $750,800,850,900$ e $950{ }^{\circ} \mathrm{C}$. Os corpos de prova foram queimados em forno elétrico (Termolab). Os ciclos de queima tiveram 4 etapas de aquecimento: $1^{\mathrm{a}}$ etapa, de 25 a $200{ }^{\circ} \mathrm{C}$ com taxa de aquecimento (T.A.) de $10{ }^{\circ} \mathrm{C} / \mathrm{min}$ e isoterma a $200{ }^{\circ} \mathrm{C}$ por 5 min; $2^{\text {a }}$ etapa, de 200 a $400{ }^{\circ} \mathrm{C}$ com T.A. de $2{ }^{\circ} \mathrm{C} / \mathrm{min}$ e isoterma a $400{ }^{\circ} \mathrm{C}$ por $10 \mathrm{~min}$; $3^{\text {a }}$ etapa, de 400 a $600{ }^{\circ} \mathrm{C}$ com T.A. de $2{ }^{\circ} \mathrm{C} / \mathrm{min}$ e isoterma a $600{ }^{\circ} \mathrm{C}$ por $5 \mathrm{~min}$; e $4^{\mathrm{a}}$ etapa, de $600{ }^{\circ} \mathrm{C}$ até a temperatura final $(750,800$, 850,900 e $950{ }^{\circ} \mathrm{C}$ ) com T.A. de $10{ }^{\circ} \mathrm{C} / \mathrm{min}$ e isoterma na 
temperatura final por $60 \mathrm{~min}$. Assim, cada ciclo iniciou com um aquecimento padrão e lento de 25 até $600{ }^{\circ} \mathrm{C}$, seguido de aquecimento até a temperatura final de queima desejada com permanência nesta temperatura por $1 \mathrm{~h}$.

Caracterização tecnológica: resistência à flexão, retração linear, absorção de água, densidade e porosidade aparente: os ensaios de caracterização tecnológica foram realizados após as medidas de consumo energético. Uma vez que a maior redução no consumo energético foi obtida com a adição de $1 \%$ em massa de aditivo, somente as amostras processadas com este percentual foram usadas para os ensaios de caracterização tecnológica. O objetivo foi avaliar se estas propriedades seriam afetadas pela presença do surfactante. Para a determinação dos valores de resistência à flexão dos corpos de prova secos foi utilizada uma máquina universal de ensaios mecânicos (Emic, DL 2000). Foram utilizados sete corpos de prova para cada composição. Os ensaios foram realizados com três pontos de apoio, velocidade de ensaio de $0,5 \mathrm{~mm} / \mathrm{min}$ e $60 \mathrm{~mm}$ de distância entre os apoios inferiores. Para a determinação da retração linear de secagem foram feitas duas marcas iniciais com um paquímetro digital (Mitutoyo) em cada corpo de prova extrudado, com distância de $75 \mathrm{~mm}$ entre as marcações. Após o processo de secagem foram realizadas medidas das novas distâncias entre as marcações e calculado o percentual de retração linear. Para as determinações da resistência à flexão e da retração linear dos corpos de prova queimados foram seguidas as mesmas metodologias utilizadas na etapa de secagem, para cada temperatura de queima. A determinação da absorção de água foi realizada conforme NBR 15310/09. A densidade aparente dos corpos de prova foi obtida pelo método de Arquimedes. A porosidade aparente, definida como o percentual volumétrico de porosidade existente no corpo de prova, foi avaliada pelo método gravimétrico.

\section{RESULTADOS E DISCUSSÃO}

Caracterização da massa argilosa. Fluorescência de raios $X$, difração de raios $X$ e análise térmica simultânea: a Tabela III apresenta a composição química da massa cerâmica expressa em termos do percentual mássico dos óxidos equivalentes e a perda ao fogo. Na Fig. 1 tem-se o difratograma desta mesma massa argilosa. Nesta massa cerâmica foram identificados principalmente picos de quartzo $(\mathrm{Q})$, caulinita (C) e goetita/hematita $(\mathrm{G})$. Os minerais foram identificados por comparação com padrões ICDD (International Centre for Diffaction Data). A presença de quartzo, caulinita, hematita/ goetita, rutilo/anatásio, plagioclásio (andesina) e feldspato alcalino já havia sido identificada em amostras de argilas primárias e secundárias do Vale do Caí [23, 24]. Uma análise criteriosa da argila principal utilizada na massa cerâmica pode ser encontrada em [23], com o código 0009-11. As fases cristalinas identificadas na caracterização mineralógica foram coerentes com os produtos esperados do processo de decomposição das rochas básicas e ácidas da região [23, 24, 28]. As argilas do Vale do Caí, independentemente da sua origem, têm como denominador comum a presença da caulinita, o que também está de acordo com o processo de formação dos solos da região a partir das rochas da Serra Geral $[23,24,28]$.

$\mathrm{O}$ resultado da análise térmica simultânea (STA) pode ser visto na Fig. 2. O pico endotérmico em torno de $100{ }^{\circ} \mathrm{C}$ e a perda de massa associada de aproximadamente $3,01 \%$ foram relacionados à eliminação de água residual. $\mathrm{O}$ pico endotérmico pequeno em aproximadamente $275{ }^{\circ} \mathrm{C}$ e a perda de massa correspondente, de cerca de $1,54 \%$, foram provavelmente devido à desidratação da goetita e formação de $\alpha-\mathrm{Fe}_{2} \mathrm{O}_{3}$ [24]. A perda de massa $(6,17 \%)$ e o pico endotérmico em torno de $522{ }^{\circ} \mathrm{C}$ podem ser atribuídos à desidroxilação da caulinita e formação de metacaulinita. O pico exotérmico em $930^{\circ} \mathrm{C}$ (sem perda de massa) pode ser explicado pela formação de $\alpha-\mathrm{Al}_{2} \mathrm{O}_{3}$ e/ou espinélio a partir da metacaulinita $[24,29]$. $\mathrm{O}$ evento endotérmico em $1155^{\circ} \mathrm{C}$ pode estar associado à formação de $\beta$-cristobalita a partir da sílica amorfa exsudada da decomposição da caulinita [30] e o pico em $1271{ }^{\circ} \mathrm{C}$ à cristalização da mulita [24].

Umidade de extrusão e dureza do extrudado: os resultados das medidas de umidade de extrusão são apresentados na Tabela IV, juntamente com os resultados de dureza do extrudado. Foi possível manter a umidade relativamente constante ao longo de todo o processo de extrusão, para as composições Ae AW1. No entanto, a dureza do extrudado da composição AW1 foi aproximadamente $37 \%$ menor que aquela da composição A. Essa redução na dureza do extrudado demonstrou a redução na viscosidade da massa, que foi consequência da dispersão mais eficiente das partículas proporcionada pela presença de $1 \%$ em massa do aditivo de processamento. Desta forma, o líquido antes aprisionado nos interstícios dos aglomerados foi disponibilizado para atuar efetivamente como veículo na mistura, efeito que resulta também em maior orientação das partículas de argila na direção do fluxo de extrusão. Esse alinhamento facilitado pelos taninos adsorvidos se reflete no aumento $(\sim 4 \%)$ da vazão média da massa aditivada (Tabela V). A melhoria na dispersão das partículas por meio da adição de tanino à mistura argila-água teve efeito direto na viscosidade da mistura. Este efeito, por sua vez, foi refletido na vazão mássica e no consumo de energia durante a extrusão, conforme pode ser observado nos resultados apresentados na

Tabela III - Composição química expressa em percentual mássico do óxido correspondente e perda ao fogo (P.F.) da massa argilosa.

[Table III - Chemical composition in wt\% of the corresponding oxide and loss on ignition (P.F.) for the clay.]

\begin{tabular}{ccccccccccr}
\hline $\mathrm{SiO}_{2}$ & $\mathrm{Al}_{2} \mathrm{O}_{3}$ & $\mathrm{Fe}_{2} \mathrm{O}_{3}$ & $\mathrm{TiO}_{2}$ & $\mathrm{MgO}$ & $\mathrm{K}_{2} \mathrm{O}$ & $\mathrm{Na}_{2} \mathrm{O}$ & $\mathrm{CaO}$ & $\mathrm{MnO}$ & $\mathrm{P}_{2} \mathrm{O}_{5}$ & P.F. \\
\hline 53,3 & 18,8 & 13,6 & 1,7 & 0,7 & 0,9 & 0,4 & 0,5 & 0,1 & 0,1 & 9,9 \\
\hline
\end{tabular}




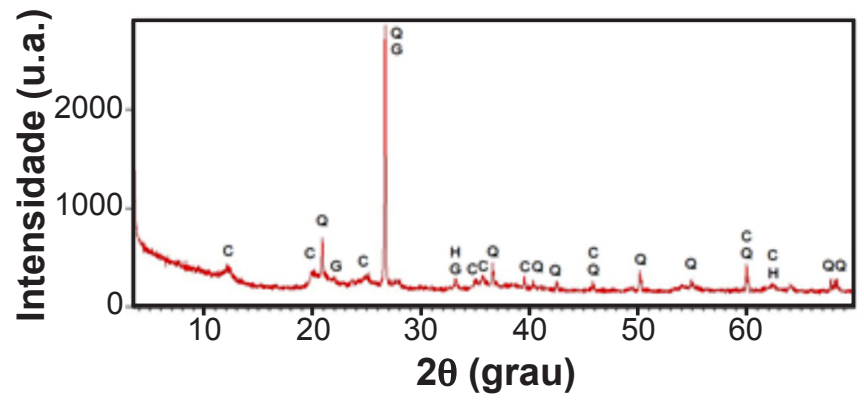

Figura 1: Difratograma de raios $\mathrm{X}$ da massa de argila utilizada: $\mathrm{Q}$ (quartzo), C (caulinita) e G (goetita/hematita).

[Figure 1: X-ray diffraction pattern of clay used: $Q$ (quartz), $C$ (kaolinite), and G (goethite/hematite).]

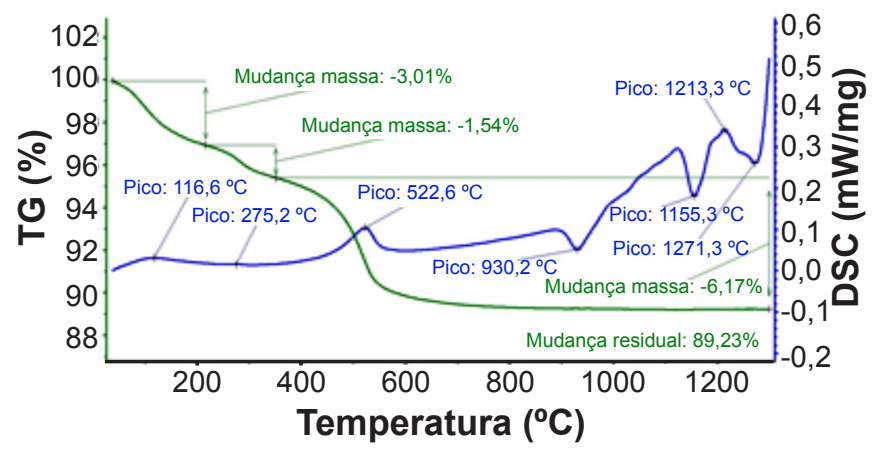

Figura 2: Análise térmica simultânea (DSC+TG) da argila utilizada. TG $(\%)$ corresponde ao percentual de massa restante.

[Figure 2: Simultaneous thermal analysis (DSC+TGA) of clay used. TG (\%) corresponds to the percentage of remaining mass.]

Tabela IV - Percentuais de umidade de extrusão e dureza do extrudado. A incerteza corresponde ao desvio padrão da média.

[Table IV - Percentages of extrusion moisture and extrudate hardness. The uncertainty is given as one average's standard deviation.]

\begin{tabular}{ccc}
\hline Composição & $\begin{array}{c}\text { Umidade de } \\
\text { extrusão }(\%)\end{array}$ & $\begin{array}{c}\text { Dureza do extrudado } \\
\left(\mathrm{kgf} / \mathrm{cm}^{2}\right)\end{array}$ \\
\hline A & $22,17 \pm 0,01$ & $2,09 \pm 0,03$ \\
AW1 & $22,51 \pm 0,08$ & $1,31 \pm 0,02$ \\
\hline
\end{tabular}

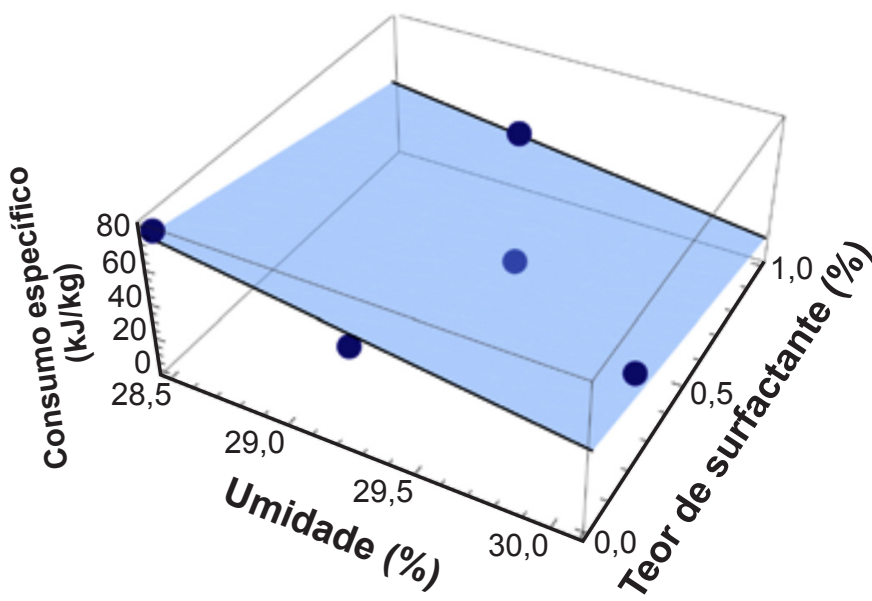

Figura 3: Efeito da umidade e do aditivo de fonte renovável sobre o consumo de energético específico na extrusão.

[Figure 3: Effect of moisture and renewable source additive on the specific energetic consumption in extrusion.]

Tabela V e Fig. 3.

A Fig. 3 representa o consumo específico de energia na extrusão (C), isto é, a energia consumida por unidade de massa do extrudado, em função da umidade da massa cerâmica e do teor de aditivo surfactante. A equação da superfície ajustada aos resultados experimentais é dada por:

$$
C=610-30 \mathrm{~S}-19 \mathrm{U}
$$

onde, $\mathrm{S}$ corresponde ao teor de surfactante e $\mathrm{U}$ à umidade da massa, ambos em base seca. Como exemplo, para um teor de umidade de $30 \%$ (base seca), a adição de $0,5 \%$ de surfactante à massa cerâmica reduz em cerca de $40 \%$ o consumo energético específico na extrusão (C), quando comparada a uma massa sem surfactante com essa mesma umidade. Conforme pode ser observado a partir da Tabela $\mathrm{V}$, a adição de $0,25 \%$ de aditivo surfactante à formulação já foi suficiente para reduzir o consumo energético da extrusora. $\mathrm{O}$ aumento progressivo do teor de aditivo reduziu ainda mais os valores de consumo energético. $\mathrm{O}$ uso de aditivo permite também o processamento de massas com teores menores de umidade, o que minimiza o tempo de processamento e a

Tabela V - Teor de umidade, corrente e potência da extrusora e vazão da massa durante o processamento de extrusão. A incerteza corresponde ao desvio padrão da média.

[Table V-Moisture content, current and power of the extruder, and flow during extrusion processing. The uncertainty is given as one standard deviation of the mean.]

\begin{tabular}{ccccccc}
\hline Composição & $\begin{array}{c}\text { Teor de } \\
\text { umidade/base } \\
\text { seca (\%) }\end{array}$ & $\begin{array}{c}\text { Teor de } \\
\text { umidade/base } \\
\text { úmida }(\%)\end{array}$ & $\begin{array}{c}\text { Corrente } \\
(\mathrm{A})\end{array}$ & $\begin{array}{c}\text { Potência } \\
(\mathrm{kW})\end{array}$ & $\begin{array}{c}\text { Vazão } \\
(\mathrm{kg} / \mathrm{h})\end{array}$ & $\begin{array}{c}\text { Consumo } \\
\text { específico } \\
(\mathrm{kJ} / \mathrm{kg})\end{array}$ \\
\hline Argila 15-08-007 & $28,5 \pm 0,2$ & $22,2 \pm 0,1$ & $7,00 \pm 0,09$ & $1,06 \pm 0,02$ & $47,2 \pm 7,9$ & $80,9 \pm 0,2$ \\
Argila 15-08-007 & $29,3 \pm 0,1$ & $22,6 \pm 0,1$ & $5,60 \pm 0,05$ & $0,79 \pm 0,01$ & $52,2 \pm 5,8$ & $54,5 \pm 0,1$ \\
Argila 15-08-007+0,25\% W & $30,1 \pm 0,1$ & $23,1 \pm 0,1$ & $4,21 \pm 0,07$ & $0,55 \pm 0,02$ & $44,6 \pm 3,6$ & $44,4 \pm 0,1$ \\
Argila 15-08-007+0,50\% W & $29,4 \pm 0,2$ & $22,8 \pm 0,1$ & $4,47 \pm 0,07$ & $0,60 \pm 0,02$ & $56,2 \pm 3,6$ & $38,4 \pm 0,1$ \\
Argila 15-08-007+1,00\% W & $29,1 \pm 0,1$ & $22,5 \pm 0,1$ & $4,19 \pm 0,07$ & $0,54 \pm 0,02$ & $54,4 \pm 4,3$ & $35,8 \pm 0,1$ \\
\hline
\end{tabular}


quantidade de peças moldadas defeituosas. Ainda há redução no custo energético durante a etapa de secagem, uma vez que a quantidade de água utilizada no processamento pode ser menor. A redução no consumo energético na extrusão é um efeito causado pela redução na viscosidade da mistura que, por sua vez, é consequência da dispersão mais eficiente das partículas cerâmicas e diminuição de aglomerados. Os resultados obtidos neste trabalho estão de acordo com o que já havia sido mencionado na literatura, com relação ao aumento na escoabilidade de massas plásticas, bem como o aumento da plasticidade da massa cerâmica [14-17, 22].

Uma observação realizada durante os ensaios de processamento é que, dependendo das características que se deseja obter nas peças finais, como por exemplo maior ou menor porosidade, seja para tijolos ou telhas, a quantidade de aditivo surfactante utilizada pode variar entre 0,25 e $1 \%$. A porosidade pode ser controlada (dados não mostrados) e ainda assim se obter redução no consumo energético na extrusão. Foi observado também que quando há excesso de água ou matéria orgânica, o efeito do aditivo surfactante é menos significativo. Dentro da faixa de concentrações explorada neste trabalho, a variação do consumo energético foi linear (conforme a Eq. A), de modo que não houve uma concentração ótima de aditivo. A concentração ótima depende do produto que se deseja obter e do custo do aditivo surfactante. Os ensaios tecnológicos foram realizados para verificar algum eventual efeito deletério da adição de surfactante nas propriedades dos corpos de prova extrudados. Portanto, nestes ensaios foi utilizada a máxima concentração estudada ( $1 \%$ em massa), para realçar qualquer efeito que pudesse ser observado.

Caracterização dos corpos de prova após a etapa de secagem. Determinação do módulo de resistência à flexão e retração linear: na Tabela VI são apresentados os resultados dos ensaios de resistência à flexão e retração linear dos corpos de prova secos. Pode-se observar que a resistência à flexão do corpo de prova aditivado com tanino foi maior do que a massa argilosa base sem o aditivo. A retração linear observada foi um pouco maior nos corpos de prova com a presença do aditivo.

Tabela VI - Resistência à flexão e retração linear para os corpos de prova secos. A incerteza corresponde ao desvio padrão da média.

[Table VI - Flexural strength and linear retraction for dry samples. The uncertainty is given as one standard deviation of the mean.]

\begin{tabular}{ccc}
\hline Composição & $\begin{array}{c}\text { Resistência à } \\
\text { flexão }\left(\mathrm{kgf} / \mathrm{cm}^{2}\right)\end{array}$ & $\begin{array}{c}\text { Retração linear } \\
(\%)\end{array}$ \\
\hline A & $67,5 \pm 2,6$ & $6,69 \pm 0,02$ \\
AW1 & $87,0 \pm 3,2$ & $6,74 \pm 0,01$ \\
\hline
\end{tabular}

Caracterização dos corpos de prova após a etapa de queima. Resistência à flexão, retração linear, absorção de água, densidade aparente e porosidade aparente: os resultados para a resistência à flexão e retração linear dos corpos de prova queimados são mostrados nas Figs. 4a e $4 \mathrm{~b}$, respectivamente. Os corpos de prova cerâmicos obtidos com a composição AW1 apresentaram resistência à flexão superior àquele dos cerâmicos obtidos com a composição A, para todas as temperaturas de queima investigadas. Este resultado pode estar relacionado com a presença do aditivo que havia proporcionado uma dispersão mais eficiente das partículas argilosas na massa a verde. $\mathrm{O}$ surfactante teria conferido maior mobilidade às partículas argilosas, facilitando seu rearranjo e proporcionando sua distribuição de forma homogênea por todo o volume das amostras, efeito já percebido nas propriedades dos corpos cerâmicos apenas extrudados (diminuição da dureza) e secos (aumento da resistência). Consequentemente, ocorreria maior uniformidade no empacotamento das partículas, a qual é refletida pela adequação e ajuste das demais propriedades mecânicas da massa AW1 frente ao processo
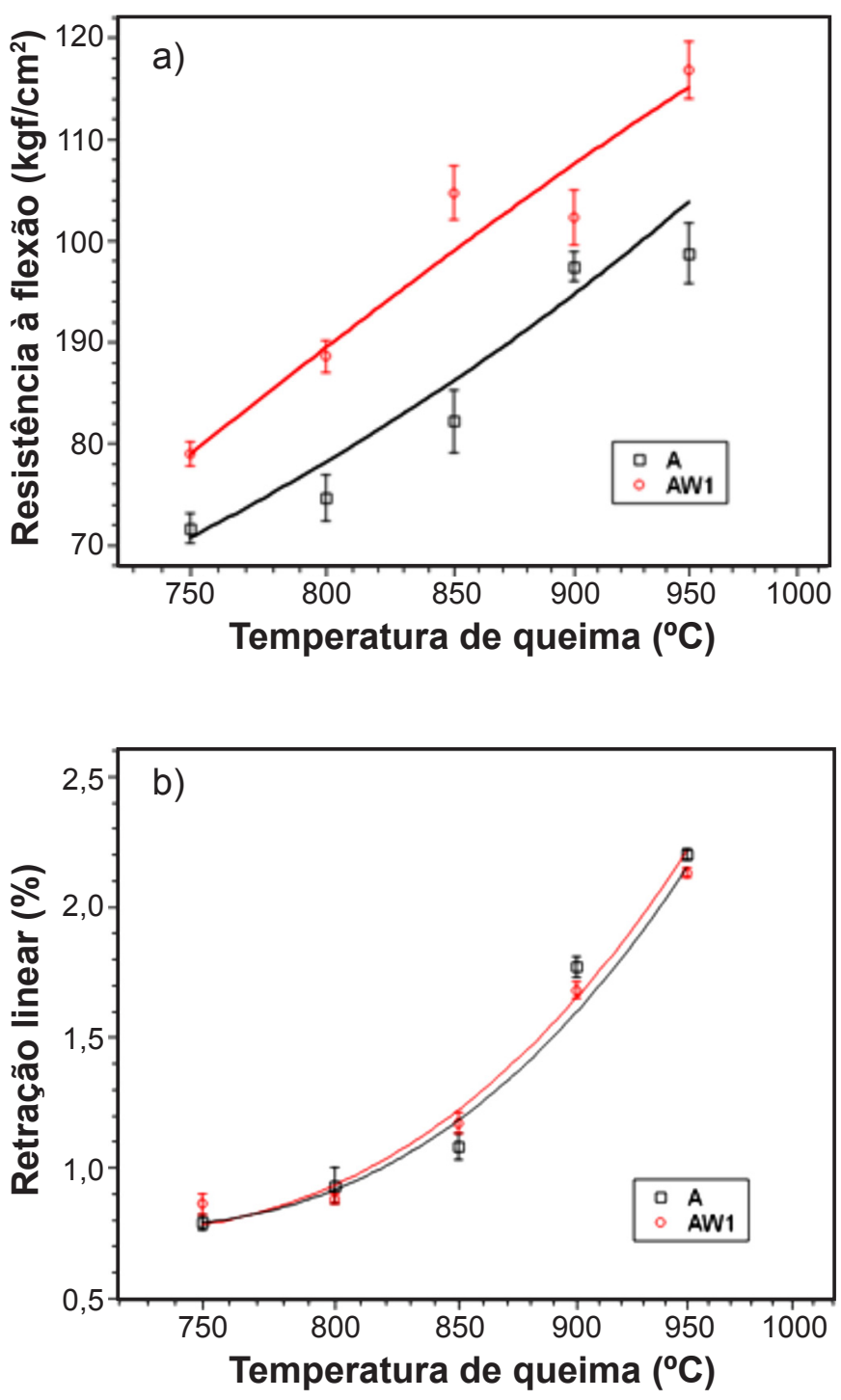

Figura 4: Resistência à flexão (a) e retração linear (b) dos corpos de prova queimados. As linhas contínuas são linhas de tendência. [Figure 4: Flexural strength (a) and linear retraction (b) of fired samples. The solid lines are trend lines.] 
de extrusão. Tendo isso em mente, poder-se-ia deduzir que esta distribuição ordenada das partículas, proporcionada pelo aditivo, poderia resultar também numa diminuição do tamanho médio de poros, como consequência do
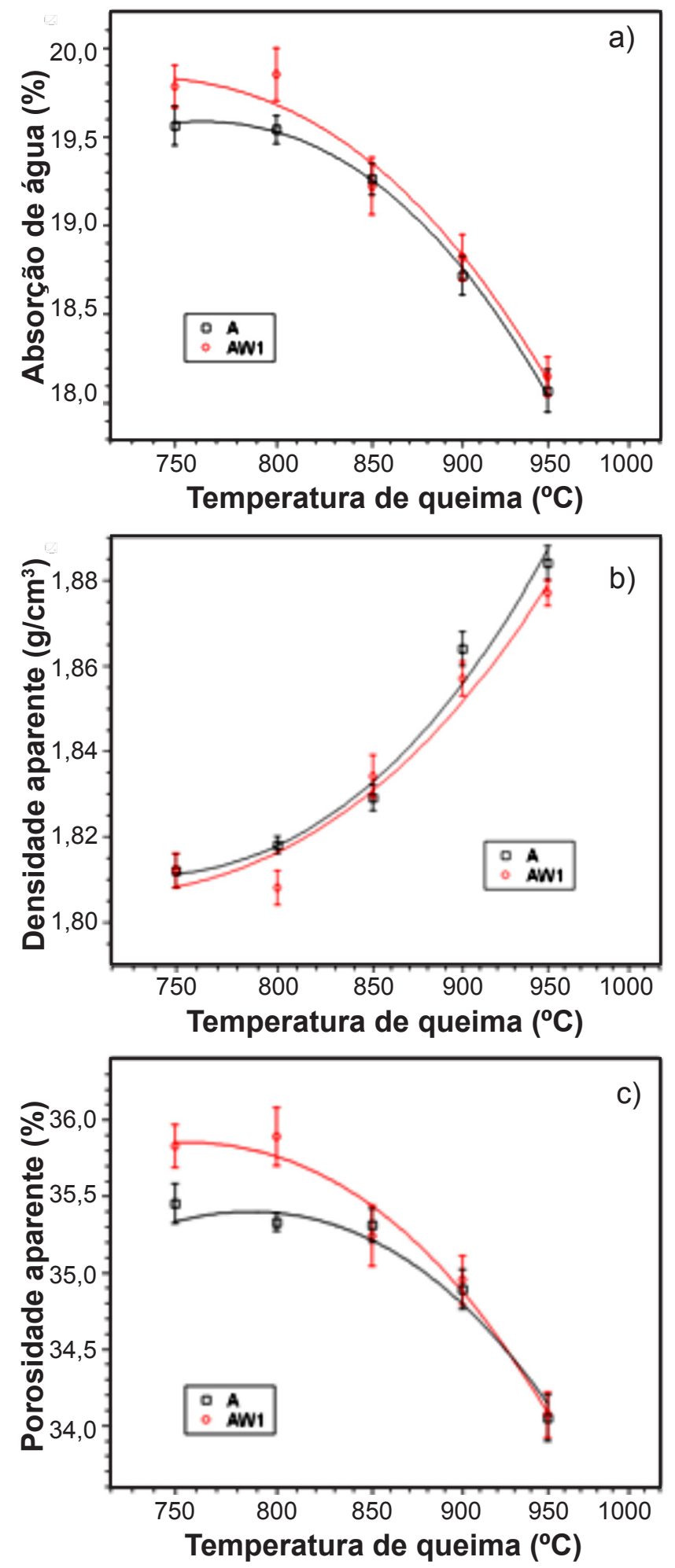

Figura 5: Absorção de água (a), densidade aparente (b) e porosidade aparente (c) dos corpos de prova queimados. As linhas contínuas são linhas de tendência.

[Figure 5: Water absorption (a), bulk density (b), and apparent porosity $(c)$ of fired samples. The solid lines are trend lines.] reordenamento derivado de um empacotamento mais regular das partículas funcionalizadas com tanino. Porém, seria razoável argumentar que o volume total de poros se manteria praticamente inalterado. Ao se admitir a homogeneização do tamanho e distribuição de poros, também poderia se esperar uma diminuição do tamanho máximo dos defeitos na estrutura formada por essas partículas, tanto a verde quanto sinterizadas. Portanto, a obtenção de arranjos ordenados de partículas, afastadas por distâncias regulares e menores, contribuiria para uma interação mais sinérgica das partículas na sinterização, o que resultaria numa massa mais resistente, como comprova a curva da massa AW1 na Fig. 4a. Como seria de se esperar, dada a argumentação anterior, não se observou diferença significativa com relação à retração linear após queima, a qual foi medida no sentido da extrusão (Fig. 4b). Um certo grau de anisotropia seria esperado se medições da retração fossem realizadas no sentido transversal ao da extrusão, mas não foi o caso neste trabalho. $\mathrm{O}$ aumento global verificado para a resistência à flexão pode ser correlacionado com o aumento da retração linear e ambos dependeram do aumento da temperatura de queima, para todos os corpos cerâmicos produzidos com as composições A e AW1. Este é um resultado esperado e observado frequentemente para silicatos, os quais são favorecidos pela sinterização com a presença de fase líquida em baixas temperaturas. Com o aumento progressivo da temperatura há o coalescimento das partículas durante o processo de sinterização (queima), o que reduz cada vez mais a porosidade entre as partículas e, assim, conduz à densificação do material.

Os resultados da determinação da absorção de água encontram-se na Fig. 5a. Assim como no caso da retração linear, não ocorreram diferenças significativas na absorção de água entre as amostras obtidas pelas composições A e AW1, principalmente para as temperaturas de queima acima de $850{ }^{\circ} \mathrm{C}$. A redução na absorção de água com o aumento da temperatura também é consequência do coalescimento das partículas, o qual reduz a quantidade de poros abertos e comunicantes dos corpos cerâmicos. Os resultados de densidade aparente dos corpos de prova encontram-se representados na Fig. 5b, enquanto os resultados de porosidade aparente são apresentados na Fig. 5c. Observa-se que a densidade também se manteve razoavelmente inalterada com a adição do surfactante. Para os corpos cerâmicos obtidos com as composições A e AW1, o aumento da densidade aparente e a redução na porosidade aparente com o aumento da temperatura de queima também foram consequência do aumento da coalescência das partículas. À medida que a temperatura de queima aumentou, houve aumento na densificação da microestrutura e redução na microporosidade. As duas propriedades estão correlacionadas, e também se correlacionam com a redução na absorção de água. Para estas propriedades, ocorreram diferenças significativas entre os corpos cerâmicos obtidos com A e AW1 apenas para a porosidade em temperaturas de queima abaixo de 
$850{ }^{\circ} \mathrm{C}$, onde AW1 resultou em maior porosidade.

\section{CONCLUSÕES}

Os resultados demonstraram que é possível utilizar um aditivo de fonte renovável, pertencente à classe dos taninos condensados, como agente dispersante em massas cerâmicas argilosas, sem comprometer as propriedades mecânicas e físicas dos corpos cerâmicos conformados e ainda reduzir o consumo energético do processo de extrusão. De fato, os resultados obtidos mostraram que, acima de $850{ }^{\circ} \mathrm{C}$, propriedades como resistência à flexão, retração linear, absorção de água, densidade e porosidade dos corpos cerâmicos obtidos a partir da composição com o surfactante (AW1) foram similares ou superiores àquelas da composição sem o dispersante (A). O efeito mais pronunciado foi na resistência à flexão, que aumentou em todas as temperaturas de queima. Sendo assim, a adição de até $1 \%$ em massa do aditivo de fonte renovável (tanino) em formulações argilosas, além de reduzir o consumo energético na extrusão, não prejudicou as propriedades avaliadas dos corpos cerâmicos obtidos.

\section{AGRADECIMENTOS}

Os autores agradecem o apoio financeiro da SDECTRS, CAPES e CNPq na realização deste trabalho. Também agradecemos ao Prof. Cláudio A. Perottoni por sua colaboração na análise dos resultados e aos funcionários do IMC que auxiliaram na execução dos experimentos.

\section{REFERÊNCIAS}

[1] J.A. Lewis, J. Am. Ceram. Soc. 83, 10 (2004) 2341.

[2] A.R. Petosa, D.P. Jaisi, I.R. Quevedo, M. Elimelech, N. Tufenkji, Environ. Sci. Technol. 44, 17 (2010) 6532.

[3] W. Liu, Z. Xie, T. Bo, X. Yang, J. Eur. Ceram. Soc. 31, 9 (2011) 1611.

[4] M.J. Rosen, Surfactants and interfacial phenomena, Wiley, New Jersey (2004).

[5] M.J. Edirisinghe, J.R.G. Evans, Mater. Sci. Eng. A 109 (1989) 17.

[6] S. Jailani, G.V. Franks, T.W. Healy, J. Am. Ceram. Soc. 91, 4 (2008) 1141.

[7] P.R. Schneider, S.B.D.A. Camillo, C.A.G. Finger, S.M.B. Frizzo, Rev. Ciênc. Florest. 9, 1 (1999) 103.

[8] R.C.V. Higa, M.S. Wrege, S. Mochiutti, A.L. Mora, A.R. Higa, A.A. Simon, in: "Agrometeorologia dos cultivos: o fator meteorológico na produção agrícola", Ed. J.E.B.A.
Monteiro, Inst. Nac. Meteor., Brasília (2009) 313.

[9] M.A. Pantoja-Castro, H. González-Rodríguez, Rev. Latinoam. Quím. 39, 3 (2011) 107.

[10] L. Falcão, M.E.M. Araújo, J. Cult. Herit. 14 (2013) 499.

[11] P.K. Ashok, K. Upadhyaya, Pharmacogn. Phytochem. 1, 3 (2012) 45.

[12] M. Oćwieja, Z. Adamczyk, M. Morga, J. Colloid Interface Sci. 438 (2015) 249.

[13] K. Khanbabaee, T. Van Ree, Nat. Prod. Rep. 18 (2001) 641.

[14] E.G. Acheson, "Manufacture of earthenware", U.S. Patent 722,791A (1903).

[15] E.G. Acheson, Trans. Am. Ceram. Soc. 6 (1904) 31.

[16] H. Salmang, Ceramics - physical and chemical fundamentals, Butterwoths, London (1961) 72.

[17] G.V. Franks, C. Tallon, A.R. Studart, M.L. Sesso, S. Leo, J. Am. Ceram. Soc. 100, 2 (2017) 458.

[18] J.C. Lamas, B.M. Cerrutti, D. de Britto, S.P. Campana Filho, E. Frollini, in: Anais $9^{\circ}$ Congr. Bras. Polím., Campina Grande (2007).

[19] B.M. Cerrutti, J.C. Lamas, M. Yokosawa, E. Frollini, in: Anais $8^{\circ}$ Congr. Bras. Polím., Águas de Lindóia (2006) 1132.

[20] B.M. Cerrutti, "Estabilização de suspensões aquosas de alumina pela adição de taninos e quitosana quaternizada", Diss. Mestr., IQ-USP, S. Carlos (2005).

[21] B.M. Cerrutti, J.C. Lamas, D. De Britto, S.P. Campana Filho, E. Frollini, J. Appl. Polym. Sci. 117 (2010) 58.

[22] M.D. Bishop, O.G. Ward, L.A. Gray, E.W. McNickle, "Clay composition containing a tannin and a method for producing bricks therefrom", U.S. Patent 6,159,886 A (2000).

[23] J.E. Zorzi, S.G. Echeverregaray, J.V. Emiliano, C.A. Perottoni, R.C.D. Cruz, Cerâmica 58, 348 (2012) 509.

[24] R.C.D. Cruz, C.A. Perottoni, J.E. Zorzi, J.V. Emiliano, Interceram 64, 1 (2015) 14.

[25] A.P.F. Albers, F.G. Melchiades, R. Machado, J.B. Baldo, A.O. Boschi, Cerâmica 48, 305 (2002) 34.

[26] P.S. Santos, Ciência e tecnologia de argilas, Vol. 1, Edgard Blücher, S. Paulo (1989).

[27] L.E. Neves, "Estudo prático de argilas por difratometria de raios X", Bol. Técn. Petrobrás 1, 1 (1968) 123.

[28] F.A. Pedron, "Mineralogia, morfologia e classificação de saprolitos e neossolos derivado de rochas vulcânicas no Rio Grande do Sul", Tese Dr., UFSM, Santa Maria (2007).

[29] H. Celik, Appl. Clay Sci. 50 (2010) 245.

[30] A.K. Chakraborty, Phase transformation of kaolinite clay, Springer, India (2014).

(Rec. 22/08/2017, Rev.21/11/2017, 28/12/2017, 15/01/2018, Ac. 22/01/2018)

(CC) BY-NC 